\title{
ARTICLES
}

\section{YOGA FOR MENOPAUSE}

Ms. Kumareswari Kandasamy*

*Registered Nurse, 4/36, West Street, Mundalapuram, Muthulapuram, Virudhunagar, Tamilnadu, India. DOI: http://doi.org/10.47211/idcij.2021.v08i03.015

ABSTRACT:

Yoga has recognized as a major role in modern society since it provides a healthy lifestyle for all age groups but it is more important for menopausal women. Natural menopause can occur between 45-55 years of women's midlife and most women spend their life with symptoms after they reach menopause. Therapeutic yoga consists of breathing techniques (Pranayama), hand gestures (Mudra), vocal tones (Mandra), gentle movements (Asana) and different forms of meditation. Hatha yoga focuses on pranayama's (breath-controlled exercises) which followed by a series of asanas (Yoga Postures), which end with savasana (a resting period). As many research has showed positive effects of yoga on menopausal symptoms. While therapeutic yoga can help to handle the women in stressful situations gracefully and adopt well to change and keep moving forward in their midlife after attain menopause.

Key Words: Yoga, Menopause, Yoga postures.

\section{ABOUT AUTHOR:}

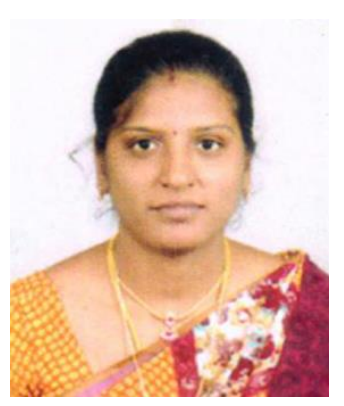

Author Ms. Kumareswari Kandasamy is working as Registered Nurse, 4/36, West Street, Mundalapuram, Muthulapuram, Virudhunagar, Tamilnadu, India. She has attended various webinars, seminars and conferences. 


\section{INTRODUCTION}

Menopause is a period of transit in the life of a woman. This brings varied experience in women some perceive it difficult while many women experience a new sense of freedom and anticipate personal growth. Menopause normally begins around the ages of 40 and 58 years in developed countries. Average age of menopause of an Indian woman is 46 years. The age of menopause is very essential for not only the loss of reproductive and chances of health troubles in midlife. During menopause, the women experience a variety of physical and psychological symptoms. Alternative therapies such as life modification, menopausal hormonal therapy, or other vitamins such as calcium, diet $D$, and micronutrients supplements can prevent many of these issues.

Yoga has recognized as a major role in modern society since it provides a healthy lifestyle for all age groups but it is more important for menopausal women. Natural menopause can occur between 45-55 years of women's midlife and most women spend their life with symptoms after they reach menopause. Yoga has been practiced as a therapeutic tool to attain positive health and improve mind and body (Vaze, 2010).

\section{Benefits of Yoga in Menopause Women}

Therapeutic yoga consists of breathing techniques (Pranayama), hand gestures (Mudra), vocal tones (Mandra), gentle movements (Asana) and different forms of meditation (Devinder Kaur, 2019). Therapeutic yoga can help to regulate sympathetic and parasympathetic nervous system Yoga poses will be a greater benefit for menopause women who feel lack of energy during menopause. Some studies have been demonstrated positive effects of yoga on menopausal symptoms such as decrease in insomnia enhance sound sleep, reduction of vasomotor symptoms and decrease in osteoporosis symptoms. Much research has been if yoga can promote positive psychophysiological changes in post-menopausal women and it enhances the overall quality of life. (Jorge 2016)

Types of Hatha yoga for menopausal symptoms

Therapeutic yoga consists of breathing techniques (Pranayama), hand gestures (Mudra), vocal tones (Mandra), gentle movements (Asana) and different forms of meditation (Devinder Kaur, 2019). There are many types of yoga. Hatha yoga is one of the most popular styles. It is a combination of many styles. However, it involves more physical type of yoga rather than other meditative form. Hatha yoga focuses on pranayama's (breath-controlled exercises) which followed by a series of asanas (Yoga Postures), which end with savasana (a resting period) (Harvard Health Publishing, 2015)

10 basic hatha Yoga Poses (Pushkar Garg, 2020)
1. Tadasana (Mountain Pose)
2. Vrikshasana (Tree Pose)
3. Uttanasana (Standing forward bend)
4. Adho Mukha Svanasana (Downward facing Dog Pose)
5. Setu Bandhasana (Bridge Pose)
6. Halasana (Plough Pose)
7. Sirsasana (Head stand)
8. Salabhasana (Locust Pose)
9. Sarvangasana (shoulder stand)
10. Dhanurasana (Bow Pose)

\section{Tadasana}

It is a simple standing posture, which forms the basis for all the standing asanas. In this asana body looks like a palm tree that is the reason it is also known as "Mountain Pose." It improves your balance and creates a sense of physical and mental balance. This asana will be repeated two or three times and gradually duration can be increased (Nirmala Mehta, 2021).

\section{Vrikshasana (Tree Pose)}

Virkshasana is a standing position that improves balance, focus and mental clarity. The asana requires the practioner to stand on one leg with the other leg bent so the foot rests on the inside of the thigh. The hands are extended overhead with palms touching. Vrikshana may also be referred to as tree pose. Stay in this position for 20 to 30 seconds with normal breathing. Repeat 5 times on each leg (Sweety, 2018)

\section{Uttanasana (Standing forward bend)}

In Uttanasana (Standing forward bend pose), Ut means intensity and the Tan means stretch extend or lengthen out. In this pose, the spine is given a deliberate and intense stretch. This yoga pose consists of standing with feet together, bending the upper body at the hips and letting the head hang downwards and taking control of the body by placing the palms on the floor besides the feet. Uttanasana is considered a base pose as uttanasana variations 
can be derived from pose. Uttanasana calms the mind while stretching and rejuvenating the whole body. Stay the pose for 30 seconds. Repeat 5 to 10 times. (Yoga journal, 2021)

\section{Adho Mukha Svanasana}

Adho mukha svanasana, also known as downward facing dog pose, is a mild inversion that calms the nervous system and helps relieve stress. During downward dog, focus on the details of your inhale and exhale to hone your attention. This pose stretches the hamstrings, calves, spine, and muscles in the back. This pose for a time of 1-3 minutes at a stretch (Gaia, 2016)

\section{Sethu Bandhasana (Bridge pose)}

Sethu Bandhasana is an asana in which the performer needs to assume the shape of a bridge. Therefore, the asana is called as sethu bandhasana or Bridge pose. The asana helps in stretching you back, neck and chest while it relaxes your body as a whole. It also strengthens your legs, back and chest. Stay in the pose from 30 seconds to 1 minute (Raghu ram Y.S. MD and Dr. Manasa, B.A.M.S, 2020)

\section{Halasana}

The asana, which gets its name from the plough, is a perfect exercise that helps in treating reproductive problems. This pose increases the blood flow to the abdominal organs and helps stimulate the thyroid and parathyroid glands too. Hence, this pose is strongly recommended for aging women. Stay for 5-10 breaths (The economic times, 2018)

\section{Sirsasana}

Sirsasana is a type of postural yoga asana (or posture) in which the body is completely inverted (headstand), and held upright supported by the forearms, while the crown of the headrests lightly on the floor. The practice of Sirsasana is postulated to increase blood flow to the brain, improving memory and other intellectual functions. In general, turning the body upside down in this way boosts the major systems of the body (circulatory, respiratory, nervous and glandular) and gives rest to the heart. Stay for 10 seconds. Gradually improve until comfortably hole the pose for 3 minutes (Nikunj J Shah, Urmi N Shah. 2009)

\section{Salabhasana}

Salabhasana is a back bending asana that opens the front of the body and strengthens the back of the body. It is performed lying on the stomach with rest the chin on the floor. Now lift your chest, arms, and legs off the floor as high as possible so that the whole body rests on the abdomen and front part of the pelvis. Hold this yoga pose for 10 seconds to 1 minute. (Nitish Kumar 2020)

\section{Sarvangasana}

It is a yoga pose wherein the whole body is balanced on the shoulders. It is also part of the padama sadhana yoga sequence. Sarv means all, anga means part of the body, and asana is posture. As the name indicates, Sarvangasana influences the functioning of all parts of your body. This asana is highly beneficial in maintaining the mental and physical health and is referred as Queen of asanas. Practice sarvangasana for 30-60 seconds (The art of living 2020)

\section{Dhanurasana}

As the name indicates, dhanu-meaning bow in Hindi, this asana makes the body form the shape of a bow as a person lie on stomach and use the hands to hold the feet while you lie on the stomach and using hands to hold the feet while stretching. When you perform the asana, your body actually resembles a stretched bow, your hands being the strings. This posture encourages a powerful stretch along the front of the body and a deep opening at the heart center, helping to cultivate an attitude of fearlessness and grace. Hold the pose for 12-15 seconds. (Plaveneeta Borah, 2016)

\section{CONCLUSION}

As many research has showed positive effects of yoga on menopausal symptoms. While therapeutic yoga can help to handle the women in stressful situations gracefully and adopt well to change and keep moving forward in their midlife after attain menopause. 


\section{REFERENCES}

1. Dr. Ishwar V. Basavaraddi (2015). Yoga: its origin, History and Development. Public Diplomacy. Available from https://mea.gov.in/in-focus-article.htm?25096/Yoga+Its+Origin+History+and+Development

2. Catherine Woodyard (2011). Exploring the therapeutic effects of yoga and its ability to increase quality of life, International Journal of yoga, 4 (2): 49-54, doi: 10.4103/0973-6131.85485

3. Hannah Nichols (2018). How does yoga work? Medical News Today Newsletter, Available from https://www.medicalnewstoday.com/articles/286745

4. Pallav Sengupta (2012). Health Impacts of yoga and pranayama: A state of the Art Review, International Journal Preventive Medicine, 3(7), 448-458. Available from https://www.ncbi.nlm.nih.gov/pmc/articles/PMC3415184/

5. Julia Belluz (2015). I read more than 50 scientific studies about yoga. Here is what I learned. Published by Voxmedia. Available from https://www.vox.com/2015/7/22/9012075/yoga-health-benefits-exercisescience.

6. Andrew Weil (2020). The 8 most popular types of yoga. Available from https://www.drweil.com/blog/spontaneous-happiness/the-8-most-popular-types-of-yoga/

7. Ann Pizer (2020). What to expect from a Hatha yoga class, very well fit, Available from https://www.verywellfit.com/what-is-hatha-yoga-

3566884\#: :text=Hatha\%20yoga\%20is\%20the\%20branch,\%2C\%20yoga\%20poses\%2C\%20and\%20meditati on.

8. Emma Newlyn (2020), What is hatha yoga?, Available from https://www.ekhartyoga.com/articles/philosophy/what-is-hatha-yoga

9. Harvard medical school (2015), Yoga - Benefits beyond the mat, Harvard Health Publishing (Available from : https://www.health.harvard.edu/staying-healthy/yoga-benefits-beyond-the-mat

10. Pushkar Garg (2020). 10 hatha yoga poses and their benefits, Fit pass, Available from : https://fitpass.co.in/blog/hatha-yoga-poses-for-beginners

11. Gaia (2016). Downward facing dog pose: Adho Mukha Svanasana. Available from https://www.gaia.com/article/downward-facing-dog-pose-adho-mukha-svanasana

12. Raghu ram Y.S. MD and Dr. Manasa, B.A.M.S, (2020). Setu bandhasana - bridge pose, how to do, benefits, Ayurveda details, Available from: https://www.easyayurveda.com/2018/04/17/setu-bandhasana-bridgepose/

13. Nikunj J Shah, Urmi N Shah. (2009). Central retinal vein occlusion following Sirsasana (headstand posture) 57, 69-70. Available from :http://www.ijo.in/article.asp?issn=03014738; year $=2009$; volume $=57$; issue $=1$; spage $=69$; epage $=70$; aulast $=$ Shah

14. Yogapedia. Available from :https://www.yogapedia.com/definition/10834/salabhasana )

15. The art of living 2020. Shoulder stand (Sarvangasana) Available from : https://www.artofliving.org/yoga/yoga-poses/shoulder-stand-sarvangasana

16. Plaveneeta Borah (2016). How to do Dhanurasana (Bow Pose): Steps and Benefits, articles from https://food.ndtv.com/health/dhanurasana-hold-that-bow-pose-to-get-rid-of-stress-1421068

17. Maninder Ahuja (2016). Age of menopause and determinants of menopause age: A PAN India survey by IMS, published by Journal of Midlife Health, 7(3), 126-131. doi: 10.4103/0976-7800.191012

18. Jorge $\mathrm{M}$ et al (2016). Hatha yoga practice decreases menopause symptoms and improves quality of life: $\mathrm{A}$ randomized controlled trial, published by complementary therapies in medicine. 26,128-35. doi: 10.1016/j.ctim.2016.03.014

19. Devinder Kaur (2019), what is therapeutic yoga? Available: https://pranashanti.com/what-is-therapeuticyoga-ottawa/

20. Shirin Mehdi ( 2017), how to do the vrikshasana and what are its benefits, available: https://www.stylecraze.com/articles/the-tree-pose-how-to-do-and-what-are-its-benefits/

21. Nitish Kumar (2020), Loctus pose/ Salabhasana steps, benefits, and precautions, Available: https://itsdarkbeforedawn.com/benefits-of-salabhasana/ 